\title{
Overview of the Injection Moulding Optimisation for Shrinkage Defect
}

\author{
${ }^{\mathrm{a}}$ Hatta N.M, ${ }^{\mathrm{a}}$ Azlan M.Z, ${ }^{\mathrm{a}}$ Roselina Sallehuddin, ${ }^{\mathrm{b}}$ Shayfull Z. \\ ${ }^{\mathrm{a}}$ Faculty of Computing \\ Universiti Teknologi Malaysia \\ 81310 UTM Johor Bahru, Johor, Malaysia \\ ${ }^{\mathrm{b}} \mathrm{School}$ of Manufacturing Engineering, \\ Universiti Malaysia Perlis, Arau, 02600, Malaysia. \\ Email: are.mallyna93@gmail.com
}

\begin{abstract}
The injection moulding process in manufacturing plastic material has become a worldwide used for more than 100 years. The used can be seen everywhere instead of becoming a daily used product. The complexity of the process makes it difficult to handle but the big production makes it possible to happen. The entire process not just involve the difficult cycling process, but the involvement of the materials which pertaining many types of characteristics which considered too. Every big production needs a quality production product with suitable cost and time efficiency. Eventhough, alongside the process, many defects can be detected by the physically seen marks. Many people, especially from the expert's field, are trying to minimise as much as they can to reduce the defects so that the residual cost can be minimised. One of the ways to overcome the problems is by simulation before the real product is being produced. The simulation is made by two classes of types which classical and non-classical method. Either both of the methods gave a good result but it still not reaches a perfect solution. In this study, the optimisation method of non-classical and classical are used to minimise the shrinkage defects at the thick plate part.
\end{abstract}

Keywords-Optimisation, injection moulding, overview, defect

\section{INTRODUCTION}

For plastic production in injection moulding process, it was reported that the process was used widely for more than 100 years [1]. Later, these past years, the process was used applied throughout many parts such as computers, everyday used products, medical devices [2], vehicle accessories, and kid's toys. In fact, plastic material has become a well-known material in numerous industries for example in agriculture, foods, aerospace and automotive. Besides, the reason behind the extensively used of the plastic production is because of the highly productive in producing various types of shape and producing a high volume of products, it just involving a small cost [3-5]. Not just that, the product produce are mostly variety in complex shape [6], thin, small and light. Focusing on the product quality, this process is gaining more and more attention because of the promising standard measure which focusing on the material used [7], part designing and parameters setting [8-10] in influencing the process so that it can be controlled. Despite that, there are some shortcoming occur alongside the process especially in maintaining the quality of the parts and cost of the products.

Through the injection moulding process, defects can normally occur and effectively affect the final characteristic of a product produce. By measuring the product quality by the defects occur, this cannot be avoided because of the mark can be clearly seen physically. As is mentioned by previous researchers, there are many defects where to be found in this process such as warpage, shrinkage, sink marks, short shots, residual stress, strength, void, flash, silver streaks, weld line and flow marks [11-13]. The reduction is happening on the perpendicular and parallel direction of the mould structure as in Fig. 1 and it has been found out that the shrinkage contributions is coming more from a perpendicular direction.

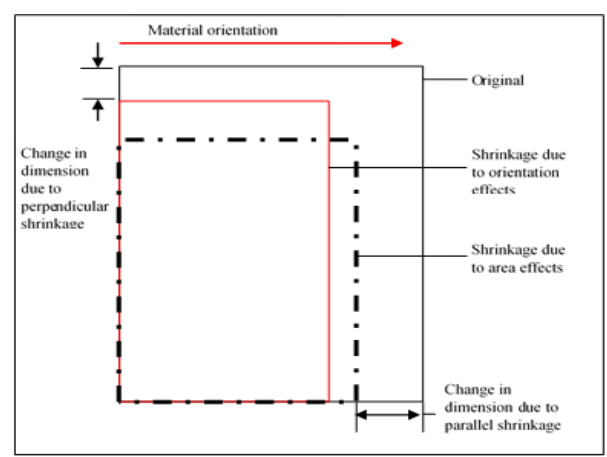

Fig 1. The definition of the shrinkage [17] 
As the major quality criterion at the finalising the product is being measured by the final geometry and shape of the product, reducing the shrinkage need to be done by optimising the parameters with a proper control. But first, the factor that makes shrinkage happened is the structure of the mould, plastic part shape, materials of the plastic and condition of the process [14]. This happened when the thermal of the plastic was changed when in the moulding process. When the shrinkage at the part being excessive, it can lead to a warpage. It has been reported that the quality of the products is low because of an improper clamping force, patchy setting, the temperature of melting and seal clearance mould. In order to achieve maximum quality, the shrinkage needs to be eliminated or reduced by process control at the parameter process $[15,16]$ and a great setup of a set of parameters setting need to be made $[17,18]$.

Process parameter setting actually gives a huge effect in the injection moulding process specifically in product quality [19-25] can make a lot of problems at the production stage such high in production cost, long lagging time and defects. For companies involved in this industry, the competitiveness of each other become low and not even give profit to them. Plus, with poor setting can lead to an insufficient system in accurateness and bothering the time of the execution [26]. The injection moulding process is an endless production process cycles in which the parameters are fixed. Because of that, the parameter needs to be adjusted close to the goal of the moulding process by using optimisation techniques.

Before this, a trial and error method in obtaining a set of parameter setting was being made by the experts and engineer in this field. Moreover, with the high cost and time consuming make this method cannot contribute much to enhancing a complex product. It turned out that, the researchers came out with solution by finding a low cost method and more time effective by implying computational techniques either by simulation on Design of Experiment (DOE) or the involvement of the coding by artificial intelligence techniques such Particle Swarm Optimisation (PSO), Genetic Algorithm (GA), Artificial Neural Network (ANN) and many more. Furthermore, to minimise the shrinkage, the optimisation method needs to be done so that, many manufacturers in this industry will get the benefit and be more competent in this field. Hence, to minimise the shrinkage, the optimisation method needs to be done so that, many manufacturers in this industry will get the benefit and be more competent in this field.

\section{OPTIMIZATION OF THE INJECTION MOLDING PROCESS BY RESPONSE SURFACE METHODOLOGY (RSM)}

The optimisation of the injection moulding process is comprised of two categories which are a classical method and non-classical method. The classical method that researchers usually used are. Taguchi method and Response Surface Methodology (RSM). RSM is actually a method to statistically design the experiment tools in form of a mathematical model which the modeling and optimising the function from various type of parameter settings. Besides, the RSM is used in order to improve the part quality by obtaining the optimum set of parameter setting and the optimum parameter. The RSM function is to be ably measuring the relationship between one or more responses. With the optimisation method of the RSM, a model and approximation of the effect of a certain experiment for every certain response can be found.

The RSM has a few useful designs and one of it known as central composite design (CCD). The CCD in RSM is developing to designing the approximate coefficients by a quadratic model when the point description will be representing in codes [27]. A CCD has three of group design which are axial points, center points, and two-level factorial.

From the previous study, Nasir et al. [28] have studied two types of gates on the shrinkage of the moulded parts. The results showed that a single gate is better than a double gate with the used Acrylonitrile Butadiene Styrene (ABS). At the end of the result, it was found that the significant factor was packing pressure. The parameter used in this study was coolant temperature, cooling time, melt temperature and packing pressure.

Isafiq et al. [29] investigated the shrinkage defects at thick plate part using RSM. This study was examined the thick plate part at the parallel and normal directions. The parameters used were packing pressure, packing time, mould temperature and melt temperature. It was found that the packing pressure was to be meant as the outstanding parameter and not just that, the optimum parameters setting for this study was obtained in this experiment. The shrinkage on the thick plate part was minimised at $14.41 \%$ for the normal direction and $42.48 \%$ for the parallel direction. Besides, Najihah et al. [30] also do the same experiment as previous literature with the same material but an addition of optimisation method known as Genetic Algorithm (GA) and the RSM. The shrinkage at the thick plate part was improved. The parameter used was melt temperature, mould temperature, packing pressure and packing time. This study has resulted that the packing pressure shown a big contribution to this research and the optimal set of parameter setting was identified.

Jeong, [31] proposed the used of the RSM in optimising the parameter setting in rib design. The material used was ABS and this study investigating the actual depth of sin marks on the specimen surfaces. In designing the design of the experiment, the researchers decided to choose BoxBehnken Design (BBD) instead of Central Composite Design (CCD) because of the suitability of the specimens. The outstanding variables they used were rib height, rib draft angle, and rib thickness. The rib thickness was discovered as most influential following the rib height and rib draft angle. This method at the end shown that to lowering the shrinkage, the rib thickness and the optimum value need to be multiplied by 0.31 at the thickness section.

Hatta et a 1.[32] studied the optimization of the shrinkage at the thick plate part using RSM and found that the shrinkage on $\mathrm{x}$-axis reduces to $1.085 \%$ and $\mathrm{y}$-axis $0.07 \%$. at the same time, the optimum parameters they obtained was $65 \mathrm{oC}$ for mold temperature, $245 \mathrm{oC}$ for melt temperature, $15.7 \mathrm{~s}$ for cooling time and $50 \mathrm{MPa}$ for packing pressure. Also, they found out that the packing pressure was most 
significant on this optimizing the shrinkage at the thick plat part.

The summary of the previous study stated before is listed in Table 2.1 below for better understanding. There are not many researchers are done during these past years especially the RSM method.

Table 1. The summarization of the RSM used from the past years

\begin{tabular}{|c|c|c|c|c|c|}
\hline 党 & 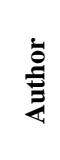 & 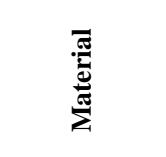 & 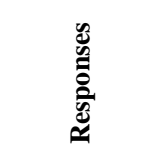 & 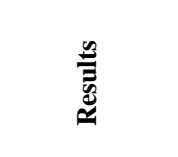 & 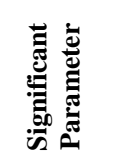 \\
\hline \multirow{6}{*}{ 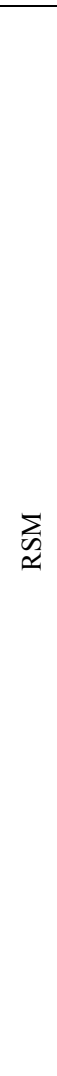 } & [31] & ABS & $\begin{array}{l}\text { Shrinkage } \\
\text { rib height, } \\
\text { rib draft } \\
\text { angle and rib } \\
\text { thickness }\end{array}$ & $\begin{array}{c}\text { Optimum } \\
\text { value by } 0.31 \\
\text { and defects } \\
\text { can be } \\
\text { lowered }\end{array}$ & $\begin{array}{c}\text { Rib } \\
\text { thickness }\end{array}$ \\
\hline & [33] & Lens & Shrinkage & $\begin{array}{c}\text { Improving } \\
\text { product } \\
\text { defects by } 5 \% \text {. }\end{array}$ & - \\
\hline & [28] & PP & Shrinkage & $\begin{array}{l}\text { The single } \\
\text { gate is better } \\
\text { than double } \\
\text { gate }\end{array}$ & $\begin{array}{l}\text { Packing } \\
\text { pressure }\end{array}$ \\
\hline & [29] & Polyethylene & Shrinkage & $\begin{array}{c}\text { Shrinkage } \\
\text { minimised at } \\
14.41 \% \\
\text { (normal } \\
\text { direction) and } \\
42.48 \% \\
\text { (parallel } \\
\text { direction) } \\
\end{array}$ & - \\
\hline & [30] & ABS & Shrinkage & $\begin{array}{c}\text { Shrinkage } \\
\text { improved by } \\
39.1 \% \\
\text { (parallel } \\
\text { direction), } \\
17.21 \% \\
\text { (normal } \\
\text { direction) } \\
\end{array}$ & $\begin{array}{l}\text { Packing } \\
\text { Pressure }\end{array}$ \\
\hline & [32] & ABS & Shrinkage & $\begin{array}{c}\text { Shrinkage on } \\
\mathrm{x} \text {-axis reduces } \\
\text { to } 1.085 \% \text { and } \\
\mathrm{y} \text {-axis } \\
0.07 \% \text {. }\end{array}$ & $\begin{array}{l}\text { Packing } \\
\text { Pressure }\end{array}$ \\
\hline
\end{tabular}

\section{Optimization Of The INJECTION MOLding PRocess BY GREY WOLVES OPTIMIZER (GWO)}

Grey Wolf Optimiser (GWO) is one of the listed metaheuristic methods in the line same with Particle Swarm Optimisation (PSO), Genetic Algorithm (GA) Artificial Neural Network (ANN) and many more. It was discovered by Seyedeli Mirjalili, Seyed Mohamad Mirjalili and Andrew Lewis in 2014. This new optimiser method has shown a great result in optimising the problem and even was successfully beating the well-known method such Particle Swarm Optimisation (PSO) in engineering design problem of compression spring, pressure vessel, and welded beam design. It also has been tested in optical buffer design to maximise the optical pulse with the highest bandwidth.

The GWO is build up based on wolf behaviors from the types of Canis Lupus from Canidae family. In the food chain, grey wolf is dominating the chart as an apex predator. The grey wolf hierarchy is existing in a pack which leading by the name of alpha, beta, delta and omega as shown in Figure 2.3. The alpha wolf is dominating the hierarchy by being a leader in a group of a grey wolf pack and can be any male or female grey wolf. The alpha will make a decision, especially in hunting, place to sleep, waking time and many more. While the beta act as a sidekick, which will help the alpha in making a decision and will be the next alpha if anything happened to the current alpha. The delta and the omega are on the lowest rank in the grey wolf pack. The delta is more like the omega but with a slight character in dominating the omega in the meantime servicing to the alpha and beta. The omega plays as the scapegoat in order to submit themselves to the other dominant wolves. It looks like the omega was not important in the pack of the wolf.

The GWO is build up based on wolf behaviours from the types of Canis Lupus from Canidae family. In the food chain, grey wolf is dominating the chart as an apex predator. The grey wolf hierarchy is existing in a pack which leading by the name of alpha, beta, delta and omega as shown in Fig.2. The alpha wolf is dominating the hierarchy by being a leader in a group of a grey wolf pack and can be any male or female grey wolf. The alpha will make a decision, especially in hunting, place to sleep, waking time and many more. While the beta act as a sidekick, which will help the alpha in making a decision and will be the next alpha if anything happened to the current alpha. The delta and the omega are on the lowest rank in the grey wolf pack. The delta is more like the omega but with a slight character in dominating the omega in the meantime servicing to the alpha and beta. The omega plays as the scapegoat in order to submit themselves to the other dominant wolves. It looks like the omega was not important in the pack of a wolf.

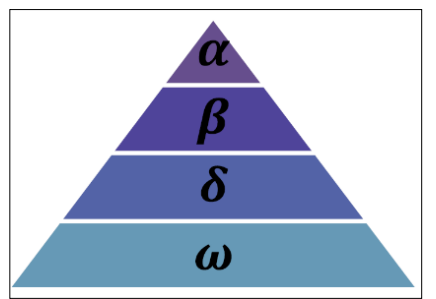

Fig.2 The hierarchy of grey wolves from top to bottom [34]

According to Muro et al. [35], the grey wolf hunting has three main phases by in Fig. 3 which are track, chase and approach the prey; pursue, encircle and harass the prey until the prey stopped from moving and attacks the prey. The behaviour of the grey wolves is then being designed by mathematical model and the optimisation is performed. 


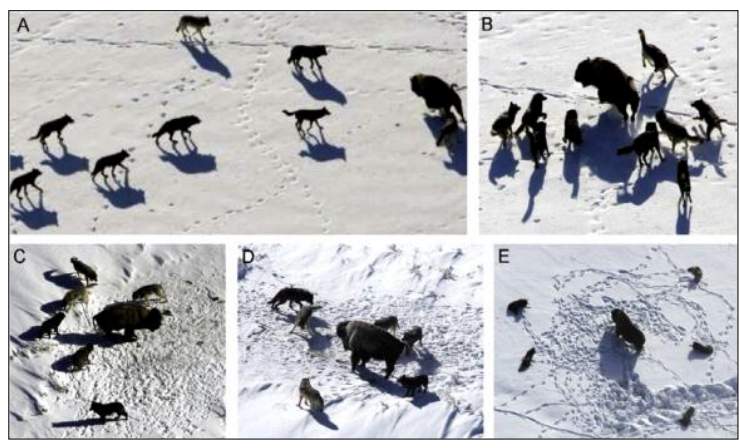

Fig. 3 The hunting behavior by the grey wolves (A) chase, approach and tracking prey (B-D) pursue, harass and encircle the prey (E) attack when the prey stopping [35]

The GWO method was not merely discovered in the plastic injection moulding process optimisation. The comparison from the previous study involving a past and recent metaheuristic method use in single optimisation method are being reviewed. Not just that, some of the researchers found a unique way in implying and enhancing the problem with more than one technique of optimisations. Either they used two or more than two methods, some of them combining the classical optimisation with nonoptimisation according to the suitability of the objectives of the study. With the various problem with yet not to come to an end, some of them also use more than one objective of the study which is mostly likable or connected to each of the defects.

\section{A. Comparison from the Previous Study}

Majunath and Krishna [9] use an Artificial Neural Network (ANN) to find the optimum parameter and the predicted error level for the Acrylonitrile Butadiene Styrene (ABS) material. The ANN used in this study to map the nonlinear input and output for various relationship or responses. The parameter used was mould temperature, injection velocity, packing pressure and melt temperature. This study shows that the ANN able to predict the error level and help the shrinkage lessen by ten and the optimum parameter setting was gained.

Wang et al. [36] also used the ANN method to find the accuracy of the shrinkage and the significant parameter was a packing pressure. The parameter used was packing time, packing pressure, melt temperature, mould temperature, fill pressure and cooling time. The plastic material used in this research is polypropylene (PP) and the shrinkage was able to reduce. Back Propagation of Neural Network (BPANN) then, was used in minimising the shrinkage. The plastic material used was a PP and the process parameter setting were consists of fill time, gate area, mould temperature, packing time and melt temperature. In order to minimise the shrinkage, the BPANN able to predict and increase the freeze time and melt temperature is found to be the significant parameter to this study.

Next, $\mathrm{Xu}$ et al. [37] used Particle Swarm Optimisation (PSO) to optimise the shrinkage problem. Using a plastic material namely as polyethylene, the study aim is to decrease the shrinkage, flash response, and weight. The parameter used was mould temperature, melt temperature, packing pressure, packing time, cooling time, injection time and injection pressure. This study obtained the optimum parameter setting for the defects and no significant parameter able to be predicted. Kitayama and Natsume [16] used a Radial Basis Function (RBF) with help of the simulated annealing algorithm in lowering the shrinkage and increase the clamping force. The parameter used were melt temperature, mould temperature, injection time, packing pressure, packing time and injection pressure. The objective of the study was able to achieve when the significant factor in contributing to the optimisation method as injection pressure was selected.

Lastly, Najihah et al., [30] use Genetic Algorithm (GA) to reduce the shrinkage at the thick plate part. The plastic material used was ABS, and the parameter used was packing time, packing pressure, melt temperature and mould temperature. This study successfully obtained the outstanding factor affecting the minimisation of the shrinkage with packing pressure. The shrinkage is able to reduce at the normal direction by $17.21 \%$ and $39.1 \%$ for parallel direction.

The comparison of the past works of literature is being reviewed according to the shrinkage defects solving optimisation problems. From the previous study, the combination of Constrained Nondominated Sorted Genetic Algorithm (CNSGA) and Back Propagation Neural Network (BPNN) produce a link between the value function and the parameter used for manufacturing mice alongside the compound cavity in injection moulding. Here, CNSGA is used to provide effectiveness in fit computational in searching method while BPNN works to give the fastest feedback to learn and give a predicted accuracy for the objective function. The parameter used is a runner of two diameters, packing pressure, cooling time and packing time. The study shows that method gain efficiency by $42 \%$ without damage to the part quality and the cost was not increased. The packing pressure was detected to be the outstanding parameter and the shrinkage at the two moulded cavities is reduced [38].

Next, the hybrid of Taguchi method with Grey Relational Analysis (GRA) and Principal Component Analysis (PCA) make an astonishing result in plastic gear manufacturing. The parameter used were melt temperature, packing time, cooling time and packing pressure. As a result, the shrinkage able to decrease by packing pressure obtained was $80 \%$, packing time $5 \mathrm{~s}$, cooling time $40 \mathrm{~s}$ and melt temperature $220^{\circ} \mathrm{C}$ (Mehat et al., 2012). The combination of BPNN and GA benefit the BPNN by searching the best fit value while BPNN works in learning to predict the accuracy in finding the optimum combination parameters. This study 
uses packing time, melt temperature, packing pressure and mould temperature as their parameter settings [39].

An Improved Efficient Global Optimisation (IEGO) work to predict the link between the shrinkage, sink marks and warpage response with the parameter consists of cooling temperature, cooling time, melt temperature, packing time, packing pressure and injection time. IEGO with help of Non-Dominated Sorting-based Genetic Algorithm II (NSGA-II) able to find the distribution and convergence of the relationship between the variable and the response. The result shows that this proposed method able to find injection time as their outstanding parameter [40]. BPNN combine with Taguchi method, PSO, Multiobjective PSO (MOPSO) and Grey Correlation Analysis (GCA) to optimise the multiobjective so that the relationship between the shrinkage, flash, and part weight and output can be mapped in a mathematical model. The parameter used were cooling time, packing time, injection time, injection pressure, mould temperature, melt temperature and packing pressure. The optimum set of the parameter was obtained at the end of this study [41].

Here, Taguchi method is combined with GRA so that the multiobjective can be executed and analysed. This study wanted to find the optimum parameter and GRA is helping Taguchi method by solving complex system and an incomplete information. The parameter used were cooling time, injection time, packing time, mould temperature, melt temperature and packing pressure. The melt temperature was found to be the significant parameter [42]. Lastly, the Taguchi method again associated with the Neural Network $(\mathrm{NN})$. The $\mathrm{NN}$ will predict the shrinkage value when the Taguchi already works to give the optimum value to this study. The parameter used was packing time, packing pressure, melt temperature and injection pressure and melt temperature revealed to be the most significant parameter [43].

From the overall recent studies, it clearly shows that the optimisation is not widely used by the latest artificial intelligence (AI) techniques. Most of the single optimisation used at least once per study and sometimes it uses in a hybrid because of the suitability and ability helping to optimise the problem. By proposing the use of the GWO optimisation method, the variety of the reference from the scope of the machine learning can be widened and be referred to the plastic injection moulding industries.

\section{CONCLUSION}

By having an overview of optimisation of injection moulding techniques, the injection moulding can be seen as one of the important parts of the manufacturing industry. Other than knowing the techniques, the process of improvement of the techniques which can develop a better result of minimising the defects also can be done in the future.

\section{ACKNOWLEDGMENT}

This work was supported by Universiti Teknologi Malaysia (UTM).

\section{REFERENCES}

[1] Hakimian, E., \& Sulong, A. B. (2012). Analysis of warpage and shrinkage properties of injection-molded micro gears polymer composites using numerical simulations assisted by the Taguchi method. Materials \& Design, 42, 62-71

[2] Öktem, H. (2012). Modeling and analysis of process parameters for evaluating shrinkage problems during plastic injection molding of a DVD-ROM cover. Journal of materials engineering and performance, 21(1), 25-32.

[3] Lin, Z. C., \& Chou, M. H. (2002). Design of the cooling channels in nonrectangular plastic flat injection mold. Journal of manufacturing systems, 21(3), 167-186.

[4] Spina, R. (2004). Injection moulding of automotive components: comparison between hot runner systems for a case study. Journal of Materials Processing Technology, 155, 1497-1504.

[5] Cho, K. J., Koh, J. S., Kim, S., Chu, W. S., Hong, Y., \& Ahn, S. H. (2009). Review of manufacturing processes for soft biomimetic robots. International Journal of Precision Engineering and Manufacturing, 10(3), 171-181.

[6] Korke, S. (1997). Analysis and measurement of warpage for linear flow of amorphous and crystalline materials.

[7] Kovács, J. G., \& Siklo, B. (2011). Test method development for deformation analysis of injection moulded plastic parts. Polymer Testing, 30(5), 543-547

[8] Yin, F., Mao, H., \& Hua, L. (2011). A hybrid of back propagation neural network and genetic algorithm for optimization of injection molding process parameters. Materials \& Design, 32(6), 3457-3464.

[9] Manjunath, P. G., \& Krishna, P. (2012). Prediction and optimization of dimensional shrinkage variations in injection molded parts using forward and reverse mapping of artificial neural networks. In Advanced Materials Research (Vol. 463, pp. 674-678). Trans Tech Publications.

[10] Li, Q., Li, L., Si, X., \& Rongji, W. (2015). Modeling the effect of injection molding process parameters on warpage using neural network theory. Journal of Macromolecular Science, Part B, 54(9), 1066-1080.

[11] Fischer, J. M. (2003). Handbook of molded part shrinkage and warpage. Plastics design library. USA: William Andrew.

[12] Harper, C. A. (2006). Handbook of plastic processes. John Wiley \& Sons.

[13] Osswald, T., \& Hernández-Ortiz, J. P. (2006). Polymer processing. Modeling and Simulation. Munich: Hanser.

[14] Chen, J. P., \& Ding, Z. P. (2012). Analysis of volumetric shrinkage and optimization of process parameters in injection molding. In Applied Mechanics and Materials (Vol. 217, pp. 2065-2069). Trans Tech Publications.

[15] Hilmi, O. M., \& Yulis, M. A. S. (2012, April). Optimising injection moulding parameters that satisfies part qualities by using Taguchi method. In Business Engineering and Industrial Applications Colloquium (BEIAC), 2012 IEEE (pp. 307-312). IEEE. 
[16] Kitayama, S., \& Natsume, S. (2014). Multi-objective optimization of volume shrinkage and clamping force for plastic injection molding via sequential approximate optimization. Simulation Modelling Practice and Theory, 48, 35-44.

[17] Shoemaker, J., \& Shoemaker, J. (2006). Moldflow design guide. Massachusetts, USA.

[18] Kazmer, D. O. (2016). Injection mold design engineering. Carl Hanser Verlag GmbH Co KG.

[19] Chien, R. D., Chen, S. C., Lee, P. H., \& Huang, J. S. (2004). Study on the molding characteristics and mechanical properties of injection-molded foaming polypropylene parts. Journal of reinforced plastics and composites, 23(4), 429444.

[20] Ismail, H., \& Suryadiansyah, S. (2004). Effects of Filler Loading on Properties of Polypropylene-Natural RubberRecycle Rubber Powder (PP-NR-RRP) Composites. Journal of reinforced plastics and composites, 23(6), 639-650.

[21] Lin, Y. H., Deng, W. J., Huang, C. H. and Yang, Y. K. Optimization of injection molding process for tensile and wear properties of polypropylene components via Taguchi and design of experiments method. Polymer-Plastics Technology and Engineering. 47(1): 96-105, (2008)

[22] Oktem, H., Erzurumlu, T., \& Uzman, I. (2007). Application of Taguchi optimization technique in determining plastic injection molding process parameters for a thin-shell part. Materials \& design, 28(4), 1271-1278.

[23] SadAbadi, H. and Ghasemi, M. Effects of some injection molding process parameters on fiber orientation tensor of short glass fiber polystyrene composites (SGF/PS). Journal of Reinforced Plastics and Composites. 26(17): 1729-1741 (2007).

[24] Chen, C. C., \& Chang, S. W. (2008). Shrinkage Analysis on Convex Shellby Injection Molding. International Polymer Processing, 23(1), 65-71.

[25] Chen, C. C., Su, P. L., \& Lin, Y. C. (2009). Analysis and modeling of effective parameters for dimension shrinkage variation of injection molded part with thin shell feature using response surface methodology. The International Journal of Advanced Manufacturing Technology, 45(11-12), 1087-1095.

[26] Mok, S. L., \& Kwong, C. K. (2002). Application of artificial neural network and fuzzy logic in a case-based system for initial process parameter setting of injection molding. Journal of Intelligent Manufacturing, 13(3), 165-176.

[27] Start-Ease, I. (2005). Design-Expert [computer software]. Minnesota: Minneapolis.

[28] Nasir, S. M., Ismail, K. A., \& Shayfull, Z. (2016). Application of RSM to Optimize Moulding Conditions for Minimizing Shrinkage in Thermoplastic Processing. In Key Engineering Materials (Vol. 700, pp. 12-21). Trans Tech Publications.

[29] Isafiq, M., Shayfull, Z., Nasir, S. M., Rashidi, M. M., Fathullah, M., \& Noriman, N. Z. (2016). Shrinkage Analysis on Thick Plate Part using Response Surface Methodology (RSM). In MATEC Web of Conferences (Vol. 78, p. 01084). EDP Sciences.

[30] Najihah, S. N., Shayfull, Z., Nasir, S. M., Saad, M. S., Rashidi, M. M., Fathullah, M., \& Noriman, N. Z. (2016). Analysis of Shrinkage on Thick Plate Part using Genetic Algorithm. In MATEC Web of Conferences (Vol. 78, p. 01083). EDP Sciences.
[31] Jeong, S. W. (2013). Optimization of a Reinforcing-Rib Design for ABS and High Glossy Surfaces of Plastic Parts. In Applied Mechanics and Materials (Vol. 330, pp. 724-729). Trans Tech Publications.

[32] Hatta, N. M., Azlan, M. Z., Shayfull, Z., Roselina, S., \& Nasir, S. M. (2017, September). Analysis of the shrinkage at the thick plate part using response surface methodology. In AIP Conference Proceedings (Vol. 1885, No. 1, p. 020152). AIP Publishing.

[33] Chen, W. C., Wang, L. Y., Huang, C. C., \& Lai, T. T. (2013). Parameter optimization of the injection molding process for a LED lighting lens using soft computing. In Advanced Materials Research (Vol. 690, pp. 2344-2351). Trans Tech Publications

[34] Mirjalili, S., Mirjalili, S. M., \& Lewis, A. (2014). Grey wolf optimizer. Advances in Engineering Software, 69, 46-61.

[35] [Muro, C., Escobedo, R., Spector, L., \& Coppinger, R. P. (2011). Wolf-pack (Canis lupus) hunting strategies emerge from simple rules in computational simulations. Behavioural Processes, 88(3), 192-197.

[36] Wang, R., Feng, X., Xia, Y., \& Zeng, J. (2013). A Back Propagation Artificial Neural Network Prediction Model of the Gate Freeze Time for Injection Molded Polypropylenes. Journal of Macromolecular Science, Part B, 52(10), 14141426.

[37] Xu, G., Yang, Z. T., \& Long, G. D. (2012). Multi-objective optimization of MIMO plastic injection molding process conditions based on particle swarm optimization. The International Journal of Advanced Manufacturing Technology, 58(5-8), 521-531.

[38] Cheng, J., Liu, Z., \& Tan, J. (2013). Multiobjective optimization of injection molding parameters based on soft computing and variable complexity method. The International Journal of Advanced Manufacturing Technology, 66(5-8), 907-916.

[39] Tan, X. H., Wang, L. G., \& Wang, W. S. (2013). Optimization of Injection Molding Process Parameters with Material Properties Based on GA and BP. In Applied Mechanics and Materials (Vol. 345, pp. 586-590). Trans Tech Publications.

[40] Zhao, J., Cheng, G., Ruan, S., \& Li, Z. (2015). Multiobjective optimization design of injection molding process parameters based on the improved efficient global optimization algorithm and non-dominated sorting-based genetic algorithm. The International Journal of Advanced Manufacturing Technology, 78(9-12), 1813-1826.

[41] Xu, G., \& Yang, Z. (2015). Multiobjective optimization of process parameters for plastic injection molding via soft computing and grey correlation analysis. The International Journal of Advanced Manufacturing Technology, 78(1-4), 525-536.

[42] Mehat, N. M., Kamaruddin, S., \& Othman, A. R. (2013). Modeling and Analysis of Injection Moulding Process Parameters for Plastic Gear Industry Application. ISRN Industrial Engineering, 2013.

[43] Dangayach, G. S., \& Kumar, D. (2012). Reduction in defect rate by Taguchi method in plastic injection molded components. In Advanced Materials Research (Vol. 488, pp. 269-273). Trans Tech Publications. 